www.nature.com/pj

\title{
Synthesis of hyperbranched fluorinated polymers with controllable refractive indices
}

\author{
Makoto Miyasaka, Naoyuki Koike, Yusuke Fujiwara, Hiroto Kudo and Tadatomi Nishikubo
}

Polymer Journal (2011) 43, 325-329; doi:10.1038/pj.2010.134; published online 12 January 2011

Keywords: fluoropolymers; hyperbranched polymer; refractive index

\section{INTRODUCTION}

Polymers containing fluorine atoms (fluorinated polymers) exhibit increased thermal stability, hydrophobicity, improved chemical resistance and decreased intermolecular attractive forces in comparison with their hydrocarbon analogs. These properties are derived from the fundamental atomic properties of fluorine, such as high ionization potential, low polarizability and high electronegativity. ${ }^{1}$ The high ionization potential, combined with the low polarizability, leads to weak intermolecular interactions, which in turn leads to low-surface energy and low refractive indices of fluorinated polymers. Recently, fluoropolymers have received considerable attention as high-performance materials for applications in optoelectronic fields. Specifically, the refractive index is a very important property of polymers for photonic applications, for which highly fluorinated polymers such as Teflon (DuPont, Wilmington, DE, USA) and CYTOP (ASAHI GLASS CO., LTD., Tokyo, Japan) are well known and widely used in optical communication networks. Current optical communication networks are based on silica optical fiber and devices. To integrate with these devices and materials, and to reduce the optical loss, polymer materials with refractive index values close to that of the silica materials (1.46) are desired. ${ }^{2}$ Therefore, materials with a controllable refractive index are required for the successful design and fabrication of photonic devices. For example, the widely used fluorinated polyimides usually have relatively low refractive indices ${ }^{3}$ and this value can be easily manipulated by introducing polar groups and copolymerizing with comonomers containing heavier atoms, such as bromine to give high refractive indices. However, it appears difficult to lower the refractive index. We have modified fluoropolymers with the simple polyaddition of bis(epoxide)s with dicarboxylic acids and diols in the presence of quaternary onium salts and they exhibited a linear relationship between refractive indices and fluorine contents of the polymer. ${ }^{4,5}$ Similar investigations have been conducted with fluorinated aromatic-aliphatic copolyethers, ${ }^{6}$ fluorinated poly (phthalazinone ether) $\mathrm{s}^{7}$ and hyperbranched fluorinated polyimides. ${ }^{8}$ The relationship between the refractive index $\left(n_{\mathrm{D}}\right)$, density $\left(\rho \mathrm{g} \mathrm{cm}^{-3}\right)$, molecular weight $\left(M \mathrm{~g} \mathrm{~mol}^{-1}\right)$ and molecular refraction $\left(R \mathrm{~cm}^{3} \mathrm{~mol}^{-1}\right)$ of a polymer is described by the Lorentz-Lorenz equation (Equation 1). ${ }^{9}$

$$
n_{\mathrm{D}}=\sqrt{\frac{M+2 \rho R}{M-\rho R}}
$$

According to the Lorentz-Lorenz equation, the polymers with low $\rho$ give low $n_{\mathrm{D}}$. That is, hyperbranched polymers (HBPs) are good candidates for the production of low-density polymers because of their three dimensional globular architecture with higher branched structure. ${ }^{10}$ Recent study has indicated that hyperbranched structures have an increasingly important role in reducing crystallinity, to avoid significant optical loss. For example, we have observed and reported that the HBPs show no birefringence due to their highly branched globular structure, preventing their polymer orientation. ${ }^{11}$ On the basis of this background information, we investigated a potentially novel approach for creating low $n_{\mathrm{D}}$ materials using HBPs consisting of bulky monomers. ${ }^{12}$

In this paper, we applied the simple polyaddition reaction to the preparation of a series of hyperbranched fluorinated polymers with different fluorine contents and comonomer structures. Furthermore, the HBPs obtained were chemically modified, and the effect of photoinitiated polymerization on refractive index was also examined.

\section{EXPERIMENTAL PROCEDURE}

Materials

The reaction solvent, $\mathrm{N}$-methyl-2-pyrroridone, and $\mathrm{o}$-dichlorobenzene were dried with $\mathrm{CaH}_{2}$ and purified by distillation before use. Tetrabutylammonium bromide (TBAB) was crystallized from ethyl acetate. Bisphenol A and 4,4biphenol were purified by recrystallization from ethyl acetate/hexane and ethanol/hexane, respectively. 2,2-Bis(4-hydroxyphenyl)hexafluoropropane (BPAF), octafluoro-4,4'-biphenol, and 1,4-bis(hexafluorohydroxyisopropyl)benzene (BFHPB) were purified by sublimation. 2-Methyl-1-[4-(methylthio)phenyl]-2-morpholinopropan-2-one (Irgacure 907, Ciba Japan K. K., Tokyo, Japan) and SP-150 (ADEKA Co., Tokyo, Japan) were used without further 
purification. 1,1',1'-Tris(4-glycidyloxyphenyl)methane (TGOPM) was prepared according to an established method. ${ }^{13}$ Unless otherwise stated, reagents were purchased from commercial suppliers and used without any further purification.

\section{Measurements}

${ }^{1} \mathrm{H}$ nuclear magnetic resonance (NMR) spectra $(500$ and $600 \mathrm{MHz})$ were obtained using JEOL JNM-ECA-600 and JEOL JNM-ECA-500 spectrometers (JEOL Ltd, Tokyo, Japan) using chloroform- $d\left(\mathrm{CDCl}_{3}\right)$ or dimethyl sulfoxide$d_{6}$ (DMSO- $\left.d_{6}\right)\left(\left(\mathrm{CD}_{3}\right)_{2} \mathrm{SO}\right)$ as the solvent. The chemical shift references were as follows: chloroform- $h, 7.26$ p.p.m.; DMSO- $d_{5}, 2.50$ p.p.m.

Infrared (IR) spectra were obtained using a Nicolet Avatar 380 FT-IR instrument (Thermo Scientific KK, Kanagawa, Japan). Real-time Infrared absorption spectra were recorded on a BIO-RAD Excalibur FTS-3000MX spectrometer (Bio-Rad Laboratories, K.K., Tokyo, Japan) equipped with a HOYA-SCHOTT EX250 UV light source (USHIO INC., Tokyo, Japan).

The number-average molecular weight $\left(M_{\mathrm{n}}\right)$ and molecular weight distribution (weight-average molecular weight/number-average molecular weight $\left(M_{\mathrm{w}} /\right.$ $\left.M_{\mathrm{n}}\right)$ ) values of the polymers were estimated on a TOSOH size-exclusion chromatography system (HLC-8220; TOSOH Corp., Tokyo, Japan), which was equipped with four consecutive polystyrene gel columns (Shodex gels: GF-1G 7B, GF310-HQ $\times 2$ and GF510-HQ; TOSOH Corp.), a refractive-index detector (RI-8022; TOSOH Corp.) and an ultraviolet detector (UV-8020; TOSOH Corp.) at $40^{\circ} \mathrm{C}$. The system was operated at a flow rate of $0.60 \mathrm{ml} \mathrm{min}^{-1}$ using a $\mathrm{N}, \mathrm{N}$-dimethyl formamide solution $(20 \mathrm{~mm} \mathrm{LiBr}$ and

\section{Table 1 Polyaddition of TGOPM $\left(B_{3}\right)$ with BPA $\left(M_{1}\right)$ or BPAF $\left(M_{2}\right)^{a}$}

\begin{tabular}{|c|c|c|c|c|c|c|}
\hline Polymer & $\begin{array}{l}\text { Feed ratio } \\
M_{1} / M_{2} / B_{3}\end{array}$ & Yield $(\%)$ & $\mathrm{M}_{n}^{\mathrm{c}}\left(\times 10^{3}\right)$ & $\mathrm{M}_{w} \mathrm{M}_{n}^{\mathrm{c}}$ & $\mathrm{T}_{g}{ }^{\mathrm{d}}\left({ }^{\circ} \mathrm{C}\right)$ & $\mathrm{n}_{D}{ }^{\mathrm{e}}$ \\
\hline $\mathrm{HBP}_{\mathrm{a}}-1$ & $3 / 0 / 2$ & 76 & 2.0 & 2.2 & 67 & 1.608 \\
\hline $\mathrm{HBP}_{\mathrm{a}}-2$ & $2 / 1 / 2$ & 83 & 2.4 & 4.2 & 78 & 1.592 \\
\hline $\mathrm{HBP}_{\mathrm{a}}-3$ & $1 / 2 / 2$ & 73 & 3.2 & 4.0 & 94 & 1.572 \\
\hline $\mathrm{HBP}_{\mathrm{a}}-4$ & $0 / 3 / 2$ & 88 & 3.8 & 4.8 & 100 & 1.567 \\
\hline
\end{tabular}

Abbreviations: BPA, bisphenol A; BPAF, bisphenol AF; TBAB, tetrabutylammonium bromide; TGOPM, 1,1',

1 "-tris(4-glycidyloxyphenyl)methane.

Conditions: tris(epoxide) $\left(B_{3}, 0.2 \mathrm{mmol}\right)$, diol $\left(\mathrm{M}_{1}, \mathrm{M}_{2}, 0.3 \mathrm{mmol}\right)$, TBAB $(5.0 \mathrm{~mol} \%)$ and o-dichlorobenzene $(0.6 \mathrm{ml})$ at $100^{\circ} \mathrm{C}$ for $2 \mathrm{~h}$.

b $n$-Hexane insoluble parts.

${ }^{c}$ Estimated by size-exclusion chromatography (eluent: $\mathrm{N}, \mathrm{N}$-dimethyl formamide) based on polystyrene standards.

${ }^{d}$ Determined by differential scanning calorimeter at heating rate $10^{\circ} \mathrm{C}-\mathrm{min}^{-1}$ under $\mathrm{N}_{2}$.

${ }^{\mathrm{e}}$ Average value of refractive index determined by ellipsometer with $632.8 \mathrm{~nm}$ laser ray.
$20 \mathrm{~mm}$ phosphoric acid) as an eluent. In this size-exclusion chromatography system, polystyrene standards were used for calibration.

The glass transition temperature $\left(T_{\mathrm{g}}\right)$ was measured with an EXSTAR 6000/ DSC6200 (SEIKO Instruments Inc., Chiba, Japan) at a heating rate of $10{ }^{\circ} \mathrm{C} \mathrm{min}^{-1}$ under a nitrogen atmosphere (monitoring range: -30 to $200{ }^{\circ} \mathrm{C}$ ).

The thermal decomposition temperature $\left(T_{\mathrm{d}}\right)$ was measured with an EXSTAR 6000/TG/DTA6200 (SEIKO Instruments Inc.) at a heating rate of $10^{\circ} \mathrm{C} \mathrm{min}^{-1}$ under a nitrogen atmosphere (monitoring range: $50-600^{\circ} \mathrm{C}$ ).

The refractive index of the polymer film was determined by ellipsometry (DHA-OLX/S4, Mizojiri Optical Co. Ltd, Tokyo, Japan). The thin film (about $1000 \AA$ in thickness) was prepared from the polymer solution (toluene or tetrahydrofuran), followed by spin coating on a silicon wafer and drying in vacuo at room temperature overnight $(>12 \mathrm{~h})$.

\section{Synthesis of polymers}

Synthesis of $\mathrm{HBP}_{a^{-1}}$ by polyaddition of TGOPM with bisphenol A. A typical procedure for the polyaddition of TGOPM and phenol derivatives was as follows: a mixture of TGOPM $(92 \mathrm{mg}, 0.2 \mathrm{mmol})$, bisphenol A $(68 \mathrm{mg}$, $0.3 \mathrm{mmol})$ and TBAB $(9.7 \mathrm{mg}, 5 \mathrm{~mol} \%)$ in $o$-dichlorobenzene $(0.6 \mathrm{ml})$ was stirred at $100{ }^{\circ} \mathrm{C}$ for $2 \mathrm{~h}$ under inert atmosphere. The reaction mixture was poured into hexane to precipitate the polymer. The resulting polymer was precipitated twice from tetrahydrofuran to hexane and water. The precipitate was collected and dried under vacuum for $24 \mathrm{~h}$. The yield of corresponding polymer was $0.12 \mathrm{~g}(76 \%) . M_{\mathrm{n}}=2.0 \times 10^{3}, M_{\mathrm{w}} / M_{\mathrm{n}}=2.2$. IR $\left(\mathrm{cm}^{-1}\right): 3401\left(v_{\mathrm{OH}}\right)$, 1608,1508 ( $v_{\mathrm{C}=\mathrm{C}}$ aromatic), 1299,1041 ( $v_{\mathrm{C}-\mathrm{O}-\mathrm{C}}$ ether). ${ }^{1} \mathrm{H}$ NMR $(600 \mathrm{MHz}$, DMSO- $d_{6}$, tetramethylsilane (TMS)): $\delta=1.54\left(\mathrm{~s}, 6.0 \mathrm{H}, \mathrm{CH}_{3}\right), 2.65-2.70(\mathrm{~m}, 0.9 \mathrm{H}$, epoxy- $\left.\mathrm{CH}_{2}\right), 2.79-2.85\left(\mathrm{~m}, 0.9 \mathrm{H}\right.$, epoxy- $\left.\mathrm{CH}_{2}\right), 3.27-3.32(\mathrm{~m}, 1.0 \mathrm{H}$, epoxyCH- ), 3.75-3.81 (m, 1.0 H, - $\mathrm{CH}_{2}-$ epoxy), $3.92-4.04\left(\mathrm{~m}, 5.2 \mathrm{H},-\mathrm{CH}_{2}-\mathrm{CH}-\right)$, $4.14-4.22(\mathrm{~m}, 1.3 \mathrm{H}, \mathrm{CH}-\mathrm{OH}), \overline{4} .22-4.30\left(\mathrm{~m}, 0.9 \mathrm{H},-\mathrm{CH}_{2}-\right.$ epoxy $), 5.31-5.37$ $(\mathrm{m}, 1.3 \mathrm{H}, \mathrm{CH}-\mathrm{OH}), \overline{5.38-5.46}\left(\mathrm{~m}, 0.7 \mathrm{H},(\mathrm{Ph})_{3} \mathrm{CH}\right), \overline{6.62-7.12}(\mathrm{~m}, 16.8 \mathrm{H}$, aromatic $\mathrm{H}), 9.11-9.18(\mathrm{~m}, 0.7 \mathrm{H}, \mathrm{Ph}-\mathrm{OH})$.

Synthesis of $\mathrm{HBP}_{b^{-1}}$ by polyaddition of TGOPM with 4,4-biphenol. Yield=91\%. $M_{\mathrm{n}}=1.6 . \times 10^{3}, M_{\mathrm{w}} / M_{\mathrm{n}}=1.7 . \quad$ IR $\left(\mathrm{cm}^{-1}\right): 3378\left(v_{\mathrm{OH}}\right), 1608,1501 \quad\left(v_{\mathrm{C}=\mathrm{C}}\right.$ aromatic), 1290,1045 ( $v_{\mathrm{C}-\mathrm{O}-\mathrm{C}}$ ether). ${ }^{1} \mathrm{H}$ NMR $\left(600 \mathrm{MHz}, \mathrm{DMSO}-d_{6}\right.$, TMS): $\delta=2.57-2.65\left(\mathrm{~m}, 1.2 \mathrm{H}\right.$, epoxy- $\left.\mathrm{CH}_{2}\right), 2.71-2.77\left(\mathrm{~m}, 1.1 \mathrm{H}\right.$, epoxy- $\left.\mathrm{CH}_{2}\right), 3.18$ $3.25\left(\mathrm{~m}, 1.2 \mathrm{H}\right.$, epoxy-CH-), 3.64-3.75 (m, $\left.1.5 \mathrm{H},-\mathrm{CH}_{2}-\mathrm{epoxy}\right), 3.79-4.12(\mathrm{~m}$, $10.2 \mathrm{H},-\mathrm{CH}_{2}-\mathrm{CH}-\mathrm{CH}_{2}-\overline{)}, 4.15-4.26\left(\mathrm{~m}, 1.3 \mathrm{H},-\mathrm{CH}_{2}\right.$-epoxy), $5.34(\mathrm{br}, 3.0 \mathrm{H}$, $\left.(\mathrm{Ph})_{3} \mathrm{CH}, \overline{\mathrm{OH}}\right), \overline{6.71}-\overline{7.50}(\mathrm{~m}, 23.0 \mathrm{H}$, aromatic $\mathrm{H}), 8.53-9.82(\mathrm{br}, 0.5 \mathrm{H}, \mathrm{Ph}-\mathrm{OH})$.

Synthesis of $H B P_{c}\left(H B P_{c}-E P O X\right)$ by polyaddition of TGOPM with BFHPB. In the case of $\mathrm{TGOPM} / \mathrm{BFHPB}=2: 3 \quad(\mathrm{mmol} / \mathrm{mmol})$ (run 3 in Table 3 ): Yield $=60 \% . M_{\mathrm{n}}=5.3 \times 10^{3}, M_{\mathrm{w}} / M_{\mathrm{n}}=2.4$. IR $\left(\mathrm{cm}^{-1}\right): 3393\left(v_{\mathrm{OH}}\right), 1609,1584$,

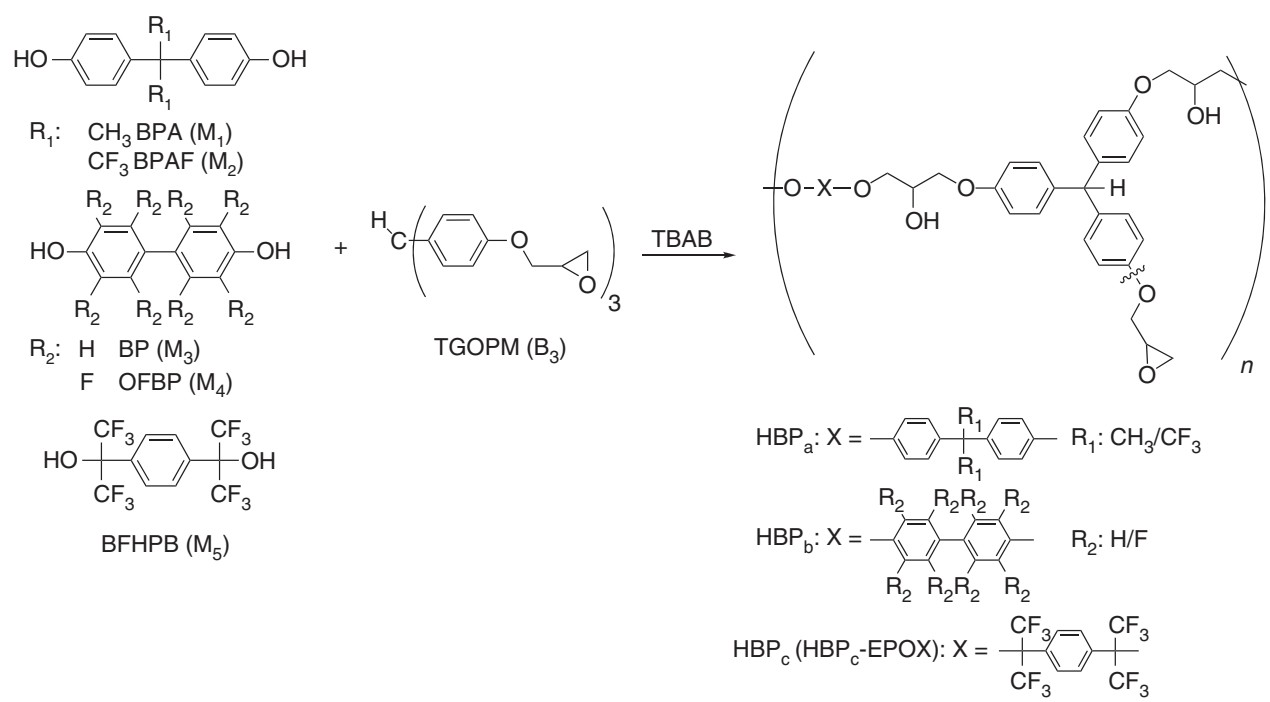

Scheme 1 Synthesis of hyperbranched polymers (HBPs). BFHPB, 1,4-bis(hexafluorohydroxyisopropyl)benzene; BP, 4,4-biphenol; BPA, bisphenol A; OFBP, octafluoro-4,4'-biphenol; TBAB, tetrabutylammonium bromide; TGOPM, 1,1',1'-tris(4-glycidyloxyphenyl)methane. 
1509, ( $v_{\mathrm{C}=\mathrm{C}}$ aromatic), 1298, 1049 ( $v_{\mathrm{C}-\mathrm{O}-\mathrm{C}}$ ether $), 1222,1198\left(v_{\mathrm{C}-\mathrm{F}}\right) .{ }^{1} \mathrm{H}$ NMR $\left(600 \mathrm{MHz}, \mathrm{CDCl}_{3}, \mathrm{TMS}\right): \delta=2.67-2.76\left(\mathrm{~m}, 0.8 \mathrm{H}\right.$, epoxy-CH$\left.{ }_{2}\right), 2.81-2.92(\mathrm{~m}$, $0.7 \mathrm{H}$, epoxy- $\left.\mathrm{CH}_{2}\right), 3.28-3.36(\mathrm{~m}, 0.8 \mathrm{H}$, epoxy-CH-), 3.48-4.37 (m, $12.8 \mathrm{H}$, $\mathrm{CH}_{2}-\mathrm{CH}-\mathrm{CH}_{2}-,-\mathrm{CH}_{2}-$ epoxy), $5.39\left(\mathrm{~m}, 2.1 \mathrm{H},(\overline{\mathrm{Ph}})_{3} \mathrm{CH}, \mathrm{OH}\right), 6.61-7.08(\mathrm{~m}$, $12.0 \mathrm{H}$, aromatic $\overline{\mathrm{H}}), \quad 7.54-7.81(\mathrm{~m}, \quad 5.3 \mathrm{H}$, aromatic $\mathrm{H}) . \quad T_{\mathrm{g}}=92^{\circ} \mathrm{C}$. $T_{\mathrm{d}}^{5 \%}=377^{\circ} \mathrm{C}$

\section{Introduction of photo-functional group}

Synthesis of $H B P_{c^{-}} \mathrm{OX}$. A typical procedure for the introduction of photofunctional group was as follows: a mixture of $\mathrm{HBP}_{\mathrm{c}}$-EPOX (terminal epoxy content $>99 \%$; $200 \mathrm{mg})$, 3-carboxy-3-ethyloxethane $(260 \mathrm{mg}, 2.0 \mathrm{mmol})$ and TBAB ( $15 \mathrm{mg}, 46 \mu \mathrm{mol}, 2.25 \mathrm{~mol} \%)$ in $N$-methyl-2-pyrroridone $(2.0 \mathrm{ml})$ was stirred at $60{ }^{\circ} \mathrm{C}$ for $36 \mathrm{~h}$ under inert atmosphere. The reaction mixture was poured into water/methanol (1:1) to precipitate the polymer. The resulting polymer was re-precipitated from tetrahydrofuran to hexane. The precipitate was collected and dried under vacuum for $24 \mathrm{~h}$. The yield of HBPc-OX was $0.14 \mathrm{~g}$ with degree of introduction $=91 \%$. IR $\left(\mathrm{cm}^{-1}\right): 3417\left(v_{\mathrm{OH}}\right), 1734\left(v_{\mathrm{C}=\mathrm{O}}\right.$ ester), 1608, 1584, 1509, ( $v_{\mathrm{C}=\mathrm{C}}$ aromatic), 1222, $1198\left(v_{\mathrm{C}-\mathrm{F}}\right), 977$ ( $v_{\mathrm{C}-\mathrm{O}-\mathrm{C}}$ cyclic ether). ${ }^{1} \mathrm{H}$ NMR $\left(500 \mathrm{MHz}, \mathrm{DMSO}-d_{6}\right.$, TMS): $\delta=0.70-0.80(\mathrm{~m}, 3.0 \mathrm{H}$, oxetane- $\left.\mathrm{CH}_{2} \mathrm{CH}_{3}\right), 1.85-1.96\left(\mathrm{~m}, 1.8 \mathrm{H}, \mathrm{CH}_{2} \mathrm{CH}_{3}\right), 3.50-4.45\left(\mathrm{~m}, 15.8 \mathrm{H},-\mathrm{CH}_{2}-\right.$ $\left.\mathrm{CH}-\mathrm{CH}_{2}-\right), 4.65-4.73\left(\mathrm{~m}, 1.9 \mathrm{H}\right.$, oxethane- $\left.\mathrm{CH}_{2}\right), 5.35-5.42(\mathrm{~m}, 1.8 \mathrm{H}, \overline{\mathrm{OH}})$, $5.50-5.60\left(\mathrm{~m}, 1.8 \mathrm{H}\right.$, oxethane- $\left.\mathrm{CH}_{2}\right), 6.75-7.00(\mathrm{~m}, 12.7 \mathrm{H}$, aromatic $\mathrm{H}), 7.75-$ $7.78(\mathrm{~m}, 3.3 \mathrm{H}$, aromatic $\mathrm{H})$.

Synthesis of $\mathrm{HBP}_{\mathrm{c}}$-MA. $\quad \mathrm{HBP}_{\mathrm{c}}$-methacrylic acid (MA) was also prepared by the reaction of $\mathrm{HBP}_{\mathrm{c}}$-EPOX with MA. The yield of $\mathrm{HBP}_{\mathrm{c}}$-MA was $0.22 \mathrm{~g}$ with $\mathrm{D}$ $\mathrm{I}=91 \%$. IR $\left(\mathrm{cm}^{-1}\right): 3432\left(v_{\mathrm{OH}}\right), 1719\left(v_{\mathrm{C}=\mathrm{O}}\right.$ ester $), 1638\left(v_{\mathrm{C}=\mathrm{C}}\right.$ allyl $), 1609$, $1586,1509,\left(v_{\mathrm{C}=\mathrm{C}}\right.$ aromatic), 1222, $1198\left(v_{\mathrm{C}-\mathrm{F}}\right) .{ }^{1} \mathrm{H}$ NMR $(600 \mathrm{MHz}$, DMSO$d_{6}$, TMS): $\delta=1.79-2.02\left(\mathrm{~m}, 3.0 \mathrm{H}, \mathrm{CH}_{3}\right), 3.55-4.38\left(\mathrm{~m}, 10.5 \mathrm{H},-\mathrm{CH}_{2}-\mathrm{CH}-\right.$ $\left.\mathrm{CH}_{2}-\right)$, 5.33-5.52 (m, 1.6 H, $\left.(\mathrm{Ph})_{3} \mathrm{CH}, \mathrm{OH}\right), 5.63-5.72(\mathrm{~m}, 1.0 \mathrm{H}, \mathrm{OH}), 5.52$ $5.61\left(\mathrm{~m} .0 .9 \mathrm{H},-\mathrm{C}=\mathrm{CH}_{2}\right), 6.00-6.13\left(\mathrm{~m}, 0.9 \mathrm{H},-\mathrm{C}=\mathrm{CH}_{2}\right), 6.71-7.21(\mathrm{~m}, 8.6 \mathrm{H}$, aromatic $\mathrm{H}), 7.74-7.96(\mathrm{~m}, 1.5 \mathrm{H}$, aromatic $\mathrm{H})$.

Table 2 Polyaddition of TGOPM $\left(B_{3}\right)$ with BP $\left(M_{3}\right)$ or OFBP $\left(M_{4}\right)^{a}$

\begin{tabular}{|c|c|c|c|c|c|c|}
\hline Polymer & $\begin{array}{l}\text { Feed ratio } \\
M_{3} / M_{4} / B_{3}\end{array}$ & Yield ${ }^{b}(\%)$ & $\mathrm{M}_{n}^{\mathrm{c}}\left(\times 10^{3}\right)$ & $\mathrm{M}_{w} \mathrm{M}_{n}^{\mathrm{c}}$ & $\mathrm{T}_{g}^{\mathrm{d}}\left({ }^{\circ} \mathrm{C}\right)$ & $\mathrm{n}_{D}^{\mathrm{e}}$ \\
\hline $\mathrm{HBP}_{\mathrm{b}}-1$ & $3 / 0 / 2$ & 91 & 1.6 & 1.7 & 71 & 1.634 \\
\hline $\mathrm{HBP}_{\mathrm{b}}-2$ & $2 / 1 / 2$ & 84 & 2.4 & 3.9 & 85 & 1.609 \\
\hline $\mathrm{HBP}_{\mathrm{b}}-3$ & $1 / 2 / 2$ & 85 & 3.9 & 5.8 & 92 & 1.585 \\
\hline $\mathrm{HBP}_{\mathrm{b}}-4$ & $0 / 3 / 2$ & 81 & 3.0 & 2.8 & 93 & 1.572 \\
\hline
\end{tabular}

Abbreviations: BP, 4,4-biphenol; OFBP, octafluoro-4,4'-biphenol; TBAB, tetrabutylammonium bromide; TGOPM, 1,1',1"-tris(4-glycidyloxyphenyl)methane.

a Conditions: tris(epoxide) $\left(B_{3}, 0.2 \mathrm{mmol}\right)$, diol $\left(\mathrm{M}_{3}, \mathrm{M}_{4}, 0.3 \mathrm{mmol}\right), \mathrm{TBAB}(5.0 \mathrm{~mol} \%)$ and o-dichlorobenzene $(0.6 \mathrm{ml})$ at $100^{\circ} \mathrm{C}$ for $2 \mathrm{~h}$.

$n$-Hexane insoluble parts.

'Estimated by size-exclusion chromatography (eluent: $\mathrm{N}, \mathrm{N}$-dimethyl formamide) based on polystyrene standards.

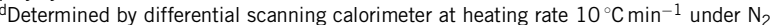

${ }^{e}$ Average value of refractive index determined by ellipsometer with $632.8 \mathrm{~nm}$ laser ray.

\section{Photoinitiated polymerization}

The photoinitiated polymerization of $\mathrm{HBP}_{\mathrm{c}}$-EPOX, $\mathrm{HBP}_{\mathrm{c}}$-OX and $\mathrm{HBP}_{\mathrm{c}}-\mathrm{MA}$ was performed in the film states, which were prepared with SP-150 (10 wt\%) for $\mathrm{HBP}_{\mathrm{c}}$-EPOX and $\mathrm{HBP}_{\mathrm{c}}$-OX and with Irgacure907 (3wt\%) for $\mathrm{HBP}_{\mathrm{c}}$-MA. The reaction was followed by real-time IR spectroscopy under UV irradiation with a $250 \mathrm{~W}$ high-pressure mercury lamp $\left(6 \mathrm{~mW} \mathrm{~cm}^{-2}\right.$ at $\left.254 \mathrm{~nm}\right)$ for $15 \mathrm{~min}$.

\section{RESULTS AND DISCUSSION}

\section{Synthesis and chemical modification of HBPs}

Polyadditions of TGOPM $(0.2 \mathrm{mmol})$ and bisphenol derivatives $(0.3 \mathrm{mmol})$ were conducted at $100{ }^{\circ} \mathrm{C}$ in the presence of quaternary onium salts (TBAB) as a catalyst. Using the bisphenol A and bisphenol $\mathrm{AF}$ (BPAF) with different feed ratios, the corresponding HBPs $\left(\mathrm{HBP}_{\mathrm{a}}-\right.$ $\left.1 \sim \mathrm{HBP}_{\mathrm{a}}-4\right)$ were obtained with $M_{\mathrm{n}}=2.0-3.8 \times 10^{3}$ and $M_{\mathrm{w}} / M_{\mathrm{n}}=2.2-$ 4.8 in $70-80 \%$ yield (Table 1 and Scheme 1 ).

The structure of the synthesized polymers $\left(\mathrm{HBP}_{\mathrm{a}}-1 \sim \mathrm{HBP}_{\mathrm{a}}-4\right)$ was confirmed by ${ }^{1} \mathrm{H}$ NMR and IR spectroscopy. The ${ }^{1} \mathrm{H}$ NMR spectrum showed new signals around 3.92-4.04, 4.14-4.22 and 5.31-5.37 p.p.m., which were assignable to the methylene, methane and hydoroxy groups of the obtained polymers by the ring opening of oxirane moieties. Regarding the IR spectrum, the signal intensity of cyclic ether $\left(v_{\mathrm{C}-\mathrm{O}-\mathrm{C}}=914 \mathrm{~cm}^{-1}\right)$ decreased, and characteristic new absorption was present that could be assigned to alcohol $\left(v_{\mathrm{O}-\mathrm{H}}\right.$ $\sim 3400 \mathrm{~cm}^{-1}$ ).

The other HBPs such as $\mathrm{HBP}_{\mathrm{b}}-1 \sim \mathrm{HBP}_{\mathrm{b}}-4$ and $\mathrm{HBP}_{\mathrm{c}}$ were prepared by the polyaddition of TGOPM and biphenyl derivatives (4,4-biphenol and octafluoro-4,4'-biphenol) or BFHPB. The results are summarized in Tables 2 and 3. In the case of $\mathrm{HBP}_{c}$, the polymer with the different amount of terminal epoxy was prepared by changing the feed ratio of BFHPB/TGOPM. As the feed ratio of BFHPB/TGOPM was 1.5 (run 3 in Table 3 ), $\mathrm{HBP}_{\mathrm{c}}$ with relatively high $M_{\mathrm{n}}\left(5.3 \times 10^{3}\right)$ and $63 \%$ terminal epoxy contents was obtained. When the feed ratio of BFHPB/TGOPM decreased to 0.5 (run 1 in Table 3), the corresponding $\mathrm{HBP}_{c}$ had a significant amount of glycidyl groups ( $>99 \%$ ) on the terminal that was calculated from ${ }^{1} \mathrm{H}$ NMR. The terminal functional glycidyl ether and phenol groups were controllable by changing the feed ratio of BFHPB/TGOPM. The thermal properties of these polymers were analyzed by DSC and TGA; the results are summarized in tables. Glass-transition temperatures $\left(T_{\mathrm{g}}\right)$ of the polymers were in the range of $60-100^{\circ} \mathrm{C}$. In all cases, higher $T_{\mathrm{g}}$ was observed for increasing fluorine contents and for the corresponding linear polymers. It was also found that HBPs showed lower $T_{\mathrm{g}}$ than the corresponding linear polymers.

Chemical modification of $\mathrm{HBP}_{\mathrm{c}}$-EPOX (run 1 in Table 3 ) for the synthesis of the photo-curable and refractive index change material

Table 3 Effect of feed ratio on polyaddition of TGOPM $\left(B_{3}\right)$ with BFHPB $\left(M_{5}\right)^{a}$

\begin{tabular}{|c|c|c|c|c|c|c|c|c|}
\hline Run & BFHPB (mmol) & Time (min) & Yield $(\%)$ & $\mathrm{M}_{n}^{\mathrm{c}}\left(\times 10^{3}\right)$ & $\mathrm{M}_{w} \mathrm{M}_{n}^{\mathrm{c}}$ & Terminal epoxy content (\%)d & F content & $\mathrm{n}_{D}^{\mathrm{e}}$ \\
\hline 1 & 0.2 & 300 & 69 & 1.9 & 4.3 & $>99$ & 19 & 1.531 \\
\hline 2 & 0.4 & 180 & 82 & 3.9 & 4.8 & 74 & 27 & - \\
\hline 3 & 0.6 & 130 & 63 & 5.3 & 2.4 & 63 & 30 & 1.511 \\
\hline 4 & 0.9 & 200 & 55 & 7.7 & 3.0 & 31 & 34 & - \\
\hline 5 & 1.2 & 300 & 85 & 6.7 & 2.2 & 11 & 36 & 1.500 \\
\hline 6 & 1.5 & 300 & 41 & 5.2 & 1.7 & 7 & 37 & - \\
\hline
\end{tabular}

Abbreviations: BFHPB, 1,4-bis(hexafluorohydroxyisopropyl)benzene; TBAB, tetrabutylammonium bromide; TGOPM, 1,1',1"'-tris(4-glycidyloxyphenyl)methane. ${ }^{a}$ Conditions: tris(epoxide) $\left(\mathrm{B}_{3}, 0.4 \mathrm{mmol}\right)$, diol $\left(\mathrm{M}_{5}, 0.2,0.4,0.6,0.9,1.2,1.5\right)$, TBAB $(5.0 \mathrm{~mol} \%)$, and o-dichlorobenzene $(1.2 \mathrm{ml})$ at $100{ }^{\circ} \mathrm{C}$.

$\mathrm{b}_{n}$-hexane insoluble parts.

cEstimated by size-exclusion chromatography (eluent: $N, N$-dimethyl formamide) based on polystyrene standards.

${ }^{\mathrm{d}}$ Calculated by ${ }^{1} \mathrm{H}$ nuclear magnetic resonance.

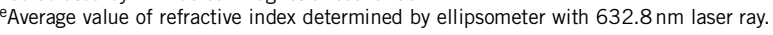






Scheme 2 Chemical modification and photoinitiated polymerization. CEO, 3-carboxy-3-ethyloxethane; HBP, hyperbranched polymer; MA, methacrylic acid; NMP, $\mathrm{N}$-methyl-2-pyrroridone; TBAB, tetrabutylammonium bromide.

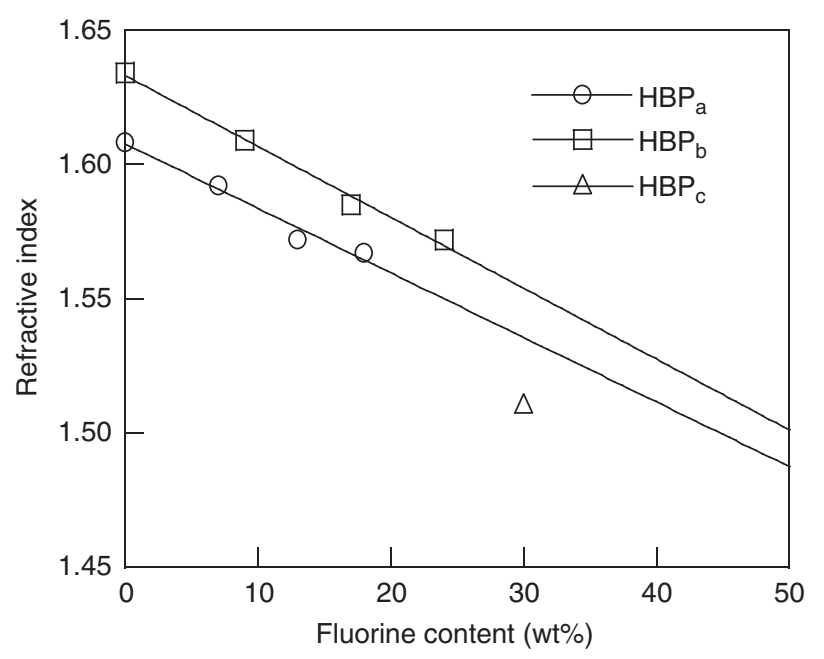

Figure 1 Relationship between the refractive index and fluorine content of hyperbranched polymers.

was examined. Addition reactions of $\mathrm{HBP}_{\mathrm{c}}$-EPOX with 3-carboxy-3ethyloxethane and methacrylic acid (MA) were carried out in the presence of TBAB in $N$-methyl-2-pyrroridone at $60^{\circ} \mathrm{C}$ for $24-48 \mathrm{~h}$. The reaction progressed efficiently, and in the IR spectra of these polymers, a new characteristic absorption peak appeared at 1734 $\left(v_{\mathrm{C}=\mathrm{O}}\right)$ for carbonyl groups, and at $1719\left(v_{\mathrm{C}=\mathrm{O}}\right)$ and $1638\left(v_{\mathrm{C}=\mathrm{C}}\right.$, allyl) for methacryloyl groups. The degrees of introduction of oxetanyl and methacryloyl groups estimated from ${ }^{1} \mathrm{H}$ NMR for both were $91 \%$ (Scheme 2).

\section{Optical properties}

A tetrahydrofuran solution of the polymer was spin-coated onto a silicon wafer and dried in vacuo at room temperature over $12 \mathrm{~h}$ to prepare a thin film with a thickness of about $0.1 \mu \mathrm{m}$. The refractive indices of polymer films were measured by ellipsometry. A linear relationship was observed between the refractive indices $\left(n_{\mathrm{D}}\right)$ and fluorine contents of the polymers $\mathrm{HBP}_{\mathrm{a}}-1 \sim \mathrm{HBP}_{\mathrm{a}}-4$ and $\mathrm{HBP}_{\mathrm{b}}-1 \sim \mathrm{HBP}_{\mathrm{b}}-4$ (Tables 1 and 2 , and Figure 1). The slopes of the refractive index against fluorine content were similar in both HBPs and corresponding LPs; however, the slope of $\mathrm{HBP}_{\mathrm{b}}$ (biphenyl structure, $-2.64 \times 10^{-3}$ ) was larger than $\mathrm{HBP}_{\mathrm{a}}$ (bisphenol structure,
Table 4 Refractive-index change of photo-functional HBPs before and after photoirradiation

\begin{tabular}{|c|c|c|c|c|}
\hline \multirow{2}{*}{ Polymer } & \multirow{2}{*}{ Conversion ${ }^{\mathrm{a}}(\%)$} & \multicolumn{2}{|c|}{ Refractive index ${ }^{\mathrm{b}}$} & \multirow{2}{*}{$\Delta \mathrm{n}_{D^{\mathrm{b}}}^{\mathrm{b}}$} \\
\hline & & Before & After & \\
\hline $\mathrm{HBP}_{\mathrm{c}}-\mathrm{EPOX}$ & 64 & 1.558 & 1.575 & +0.017 \\
\hline $\mathrm{HBP}_{\mathrm{C}}-\mathrm{OX}$ & 24 & 1.549 & 1.553 & +0.004 \\
\hline $\mathrm{HBP}_{\mathrm{c}}-\mathrm{MA}$ & 92 & 1.555 & 1.558 & +0.003 \\
\hline
\end{tabular}

aCalculated from infrared spectrum after $15 \mathrm{~min}$ irradiation.

${ }^{\mathrm{b}}$ Average value of refractive-index by the ellipsometer using $632.8 \mathrm{~nm}$ ray.

$\left.-2.40 \times 10^{-3}\right)$. This result might be due to the fluorine atom that is attached directly to the aromatic ring. The $n_{\mathrm{D}}$ of $\mathrm{HBP}_{\mathrm{a}}-1$ and $\mathrm{HBP}_{\mathrm{b}}-1$, which have no fluorine in their polymer structures, was 1.608 and 1.634 , respectively. Furthermore, the $n_{\mathrm{D}}$ values of corresponding $\mathrm{LP}_{\mathrm{a}}$ and $\mathrm{LP}_{\mathrm{b}}$ were 1.611 and 1.645 , respectively. HBPs displayed a lower $n_{\mathrm{D}}$ value than did LPs. This behavior supports the fact that HBPs have low density because of their three dimensional globular structure with a many branched arm. Notably, the difference of $\mathrm{HBP}_{\mathrm{a}}-1\left(\mathrm{LP}_{\mathrm{a}}-1\right)$ and $\mathrm{HBP}_{\mathrm{b}}-1\left(\mathrm{LP}_{\mathrm{b}}-1\right)$ could explain an $\mathrm{A}_{2}$ monomer structure because the bended bisphenol skeleton produced by $\mathrm{sp}^{3}$-hybridized carbon produces lower $n_{\mathrm{D}}$ as compared with the relatively flat biphenyl structure.

\section{Photoinitiated polymerization of $\mathrm{HBP}_{\mathrm{c}}$-EPOX, $\mathrm{HBP}_{\mathrm{c}}-\mathrm{OX}$ and $\mathrm{HBP}_{\mathrm{c}}$-MA and its optical properties}

The photoinitiated polymerization of $\mathrm{HBP}_{\mathrm{c}}$-EPOX, $\mathrm{HBP}_{\mathrm{c}}$-OX and $\mathrm{HBP}_{\mathrm{c}}$-MA was performed in the film states. The conversion of glycidyl, oxetanyl and methacryloyl groups was calculated from the decrease in the absorbance at $913\left(v_{\mathrm{C}-\mathrm{O}-\mathrm{C}}\right), 977\left(v_{\mathrm{C}-\mathrm{O}-\mathrm{C}}\right)$ and $1638 \mathrm{~cm}^{-1}\left(v_{\mathrm{C}=\mathrm{C}}\right.$ ), respectively (Table 4$)$. The conversion of $\mathrm{HBP}_{\mathrm{c}^{-}}$ MA that was reached was quite high ( $92 \%)$ because the photoinitiated radical polymerization proceeded smoothly. In contrast, in the case of photoinitiated cationic polymerization, the conversion of $\mathrm{HBP}_{\mathrm{c}}$-EPOX and $\mathrm{HBP}_{\mathrm{c}^{-}} \mathrm{OX}$ was 64 and $24 \%$, respectively. The higher conversion of glycidyl versus oxetanyl could be explained by the high reactivity of the three-member ring glycidyl due to its highly strained structure. Furthermore, the reactivity of cationic polymerization of terminal oxetanyl groups was lowered by both hydroxyl and ester groups. A comparison of the refractive index change $(\Delta n)$ of the photofunctional HBPs is summarized in Table 4. 
After the photoinitiated cationic polymerization of $\mathrm{HBP}_{\mathrm{c}}$-EPOX and $\mathrm{HBP}_{\mathrm{c}^{-}} \mathrm{OX}$, increased refractive index changes $\left(\Delta n_{\mathrm{D}}\right.$ 's) were observed because of the formation of crosslinked film with ca. 3\% shrinkage of the film thickness. The $\Delta n_{\mathrm{D}}$ 's are dependent on the change of molar refraction $(R)$ and density $(\rho)$ before and after photoirradiation. ${ }^{13}$ The difference of $\Delta n_{\mathrm{D}}$ of $\mathrm{HBP}_{\mathrm{c}}$-EPOX and $\mathrm{HBP}_{\mathrm{c}^{-}} \mathrm{OX}$ could be explained by the size of cyclic ether and the efficiency of photo-curing. The high reactivity and compact structure of glycidyl lead to higher crosslinking density, and as a consequence, $\mathrm{HBP}_{\mathrm{c}^{-}}$-EPOX shows larger $\Delta n_{\mathrm{D}}$ than $\mathrm{HBP}_{\mathrm{c}}$-OX. Notably, in the case of

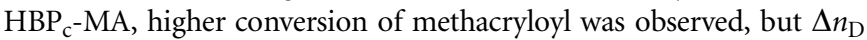
was not significantly increased.

\section{CONCLUSIONS}

In this study, we synthesized hyperbranched fluorinated polymers using a simple polyaddition reaction of phenol derivatives and TGOPM as $\mathrm{A}_{2}$ and $\mathrm{B}_{3}$ monomers, respectively. The fluorine content of the HBPs could be controlled by changing the feed ratio and the refractive index values of the HBPs, and it tended to decrease with increasing fluorine content. The $n_{\mathrm{D}}$ was also affected by the monomer and polymer structures. Cured materials tended to increase $n_{\mathrm{D}}$ because of the increase in the crosslinking density of the film.

\section{ACKNOWLEDGEMENTS}

This work was supported by a Grant-in-Aid for Young Scientists (B) (21750223) from the Ministry of Education, Science and Culture of Japan.
1 Zubia, J. \& Arrue, J. Plastic optical fibers: an introduction to their technological processes and APPLICATIONS. Opt. Fiber Technol. 7, 101-140 (2001).

2 Man, H., Jen, A. K.- J. \& Dalton, L. R. Polymer-based optical waveguides: materials, processing, and devices. Adv. Mater. 14, 1339-1365 (2002).

3 Jang, W., Shin, D., Choi, S., Park, S. \& Han, H. Effects of internal linkage groups of fluorinated diamine on the optical dielectric properties of polyimide thin film. Polymer 48, 2130-2143 (2007).

4 Ito, N., Tanosaki, S., Kudo, H., Kameyama, A. \& Nishikubo, T. Synthesis and characterization of fluoropolymers by the polyaddition of bis(epoxide)s with dicarboxylic acids and diols. J. Polym. Sci. Part A Polym. Chem. 40, 1395-1404 (2002).

5 Kudo, H., Ito, N., Nakajima, K., Ochiai, M. \& Nishikubo, T. Synthesis of refractive-index control of fluoropolymers by the polyaddition of bis(epoxide)s and triazine di(aryl ether)s. J. Polym. Sci. Part A Polym. Chem. 45, 4421-4429 (2007).

6 Ding, J., Jiang, J., Blanchetière, C. \& Callender, C. L. Highly fluorinated aromaticaliphatic copolyethers. Macromolecules 41, 758-763 (2008).

7 Song, Y., Li, G., Wang, J., Sun, Q., Jian, X., Teng, J. \& Zhang, H. Fluorinated poly(phthalazinone ether)s with tunable refractive index: synthesis, characterization and optical properties. Poly. J. 40, 92-93 (2008).

8 Gao, H., Yan, C., Guan, S. \& Jiang, Z. Hyperbranched fluorinated poluimides with tunable refractive indices for optical waveguide applications. Polymer 51, 694-701 (2010).

9 Meeten, G. H. (ed.) (Elsevier Applied Science: London, 1989)

10 Voit, B. New Developments in hyperbranched polymers. J. Polym. Sci. Part A Polym. Chem. 38, 2505-2525 (2000).

11 Maruyama, K., Kudo, H., Ikehara, T., Ito, N. \& Nishikubo, T. Synthesis of photocrosslinkable hyperbranched polyesters and their film properties. J. Polym. Sci. Part A Polym. Chem. 43, 4642-4653 (2005).

12 Miyasaka, M., Fujiwara, Y., Kudo, H. \& Nishikubo, T. Synthesis and characterization of hyperbranched polymer consisting of silsesquioxane derivatives. Polym. J. 42, 799-803 (2010).

13 Kudo, H., Ueda, W., Sejimo, K., Mitani, K., Nishikubo, T. \& Anada, T. New large refractive-index change materials: synthesis and photochemical valence isomerization of the calixarene derivatives containing norbornadiene moieties. Bull. Chem. Soc. Jpn. 77, 1415-1422 (2004). 